\title{
Rethinking Fuels
}

\section{Dear Reader,}

We owe the level of individual mobility that we know and appreciate today not least to internal combustion engines and fuels, most of which come from fossil resources. But, among other things, the combustion of these fossil fuels generates $\mathrm{CO}_{2}$ emissions that negatively affect our air quality.

A balanced carbon cycle is essential for the survival of human beings and animals. The combustion of fossil resources disturbs the balance of this cycle. We can re-establish this balance if we implement the results of the UN Climate Conference in Paris. One of the levers for achieving this is $\mathrm{CO}_{2}$-neutral traffic. Electric mobility will enable us to achieve zero emissions locally. However, electric mobility is not an all-embracing solution. Worldwide financing, long-distance mobility and heavy goods transportation are not guaranteed.

This gap can be filled by $\mathrm{CO}_{2}$-neutral fuels with their high energy density. Synthetic fuels are particularly suitable. If they can be produced on a large industrial scale, they can replace fossil-based sources of energy. They could even be used in existing vehicles. Investment for product development and an energy supply system for vehicles are available worldwide and can continue to be used. What is more, synthetic fuels can be specifically designed. As a result, they have the additional potential of soot-free combustion. That would be a breakthrough in air quality. Initial tests are promising.
But we are only at the beginning. Further investment is necessary, not only in research but also in the production of these new fuels. Specifically designed synthetic fuels give us the opportunity not only to start with some millions of new vehicles, but also with more than one billion existing vehicles - with a liberating effect for the industry. New fuels and electric mobility can lead us to sustainable, $\mathrm{CO}_{2}$-neutral and zeroemission mobility. Only both paths together will take us to our target.

In this special issue, we have put together important information on the fuels and lubricants of the future and examine them from many different aspects. We hope that we can give you new impulses and that you enjoy reading our reports.

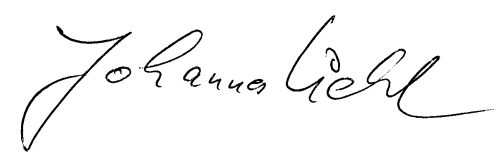

Dr. Johannes Liebl Editor-in-Charge ATZ I MTZ | ATZelektronik

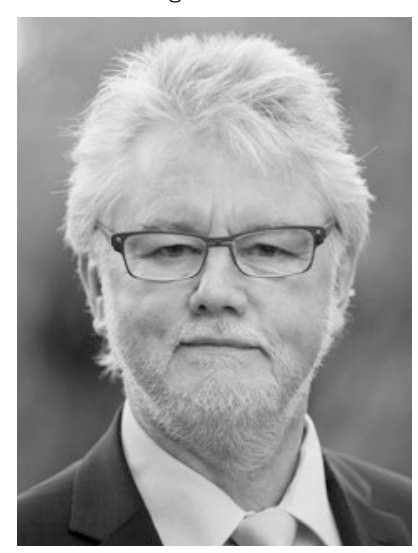

